\title{
Comparison of qPCR and blood smear microscopy for the diagnosis of Mycoplasma suis in a French veterinary practice
}

\author{
Valérie Normand ${ }^{1}$, Gwenaël Boulbria ${ }^{1 *}$ D , Mathieu Brissonnier ${ }^{1}$, Véronique Bachy², Pierre-Yves Moalic ${ }^{3}$, \\ Pauline Berton ${ }^{1}$, Franck Bouchet ${ }^{1}$ and Arnaud Lebret ${ }^{1}$
}

\begin{abstract}
Mycoplasma suis (M. suis) is an haemotropic Mycoplasma that adheres and invades erythrocytes and is responsible for infectious anaemia of pigs. Infections with M. suis have been reported worldwide. Clinical signs after M. suis infection can be significant particularly for the breeding herd in the period around farrowing but consequences are highly variable with some infected pigs never exhibiting clinical disease. The study aimed to determine the clinical relevance of Giemsa-stained blood smear for the diagnosis of $M$. suis compared with qPCR results. In our study, the comparison of qPCR results with microscopic investigation of Giemsa-stained blood smears revealed a lower sensitivity of the microscopic method: only 33 out of 102 qPCR positive blood samples were microscopically positive (M. suis visualised). No relationship between mean qPCR loads and microscopic observation was observed. Although more costly, qPCR is probably the best diagnostic tool available today for M. suis diagnosis.
\end{abstract}

Keywords: Pig, Mycoplasma suis, PCR, Blood smear, Diagnostic

\section{Background}

Mycoplasma suis (M. suis) is an uncultivable haemotropic Mycoplasma that targets red blood cells of pigs [3] and is responsible for infectious anaemia of pigs (IAP), historically known as porcine eperythrozoonosis [4]. The syndrome has two main clinical forms: an acute form with high fever and anaemia, and a chronic form with multiple and non-specific symptoms. Clinical consequences of $M$. suis infection can be very significant, particularly for the breeding herd in the period around farrowing. Infection with $M$. suis is also reported to result in decreased birth weights and poor growth in postweaning piglets [4]. M. suis direct diagnosis consists in DNA detection by qPCR or observation in blood smears. To date, microscopic observation have proven to be of low sensitivity but it is of interest for practitioners because it could be performed immediately after clinical

\footnotetext{
* Correspondence: g.boulbria@porc.spective.fr

${ }^{1}$ Porc.Spective Swine Vet Practice, ZA de Gohélève, rue Joseph et Etienne Montgolfier, 56920 Noyal Pontivy, France

Full list of author information is available at the end of the article
}

examination. A previous study described the low sensitivity of microscopic observation compared with qPCR, but the comparison was performed on post-weaning pigs (20-30 kg) supposed to be acutely diseased [7]. The objective of this study was to evaluate the clinical relevance of these two diagnostic tests for veterinary practitioners in adult pigs (sows) chronically affected.

\section{Materials and methods}

A total of 199 sows from ten farms were individually sampled in the week before farrowing. Blood was collected by venipuncture (jugular vein). Two samples were collected in Vacutest ${ }^{\circ}$ EDTA-anticoagulated tubes, one for qPCR and one for blood smears, and submitted to the diagnostic laboratory within $24 \mathrm{~h}$ under positive-cold conditions.

For qPCR, deoxyribonucleic acid (DNA) was extracted from $200 \mu \mathrm{L}$ EDTA blood samples using MagAttract 96 Cador Pathogen kit (Qiagen, Venlo, The Netherlands) following manufacturer's instructions. DNA recovery was obtained in $100 \mu \mathrm{L}$ elution buffer AVE and stored at

(c) The Author(s). 2020 Open Access This article is distributed under the terms of the Creative Commons Attribution 4.0 International License (http://creativecommons.org/licenses/by/4.0/), which permits unrestricted use, distribution, and reproduction in any medium, provided you give appropriate credit to the original author(s) and the source, provide a link to the Creative Commons license, and indicate if changes were made. The Creative Commons Public Domain Dedication waiver (http://creativecommons.org/publicdomain/zero/1.0/) applies to the data made available in this article, unless otherwise stated. 
$-20^{\circ} \mathrm{C}$. A specific plasmid containing the targeted DNA sequence of $M$. suis was constructed. This plasmid was ordered (Eurofins, Luxembourg, Luxembourg): it contained the $M$. suis PCR target sequence. Dilutions of plasmidic DNA was then used to establish a quantitation curve. Dilutions were then used for absolute quantification assays. M. suis detection was achieved using a qPCR test [2]. The reverse primer, targeting $16 \mathrm{~S}$ ribosomal DNA, was slightly modified. Following sequence alignment of French field strains of $M$. suis, reverse primer has been shifted from a base to the $3^{\prime}$ end. So that the test could be run with Labofarm's routine qPCR thermal cycle, using the Ultra-Fast qPCR kit (Agilent Technologies, Les Ulis, France). Specificity was evaluated using Mycoplasma hyopneumoniae, Mycoplasma hyorhinis, Mycoplasma hyosynoviae and Mycoplasma floculare DNA. No cross reaction was detected. The quantification limit was achieved using $M$. suis negative EDTA blood sample spiked with M. suis plasmid. The qPCR is able to detect $10^{6}$ copies of $16 \mathrm{~S}$ ribosomal DNA gene per $\mathrm{ml}$ of blood corresponding to 5 to $2.5 \times 10^{5}$ bacteria per $\mathrm{ml}$ of blood.

Giemsa-stained blood smears were prepared from EDTA-anticoagulated venous bloods using automatic Giemsa colouring with the Aerospray automaton (Elitech, Puteaux, France). They were then read on an Olympus CX41 microscope (Olympus, Tokyo, Japan) at $\times 1000$ magnification (immersion oil). Smears were examined by trained haematopathologists. Blood smears were considered positive if the presence of $M$. suis was clearly identified (Fig. 1). Doubtful samples were blood smears on which no Mycoplasma sp. could not be directly visualised but where a cytopathogenic effect on erythrocytes was observed: mostly presence of ghost cells, polychromasia and anisocytosis. For the comparison between the two diagnostic tools, we considered that the blood smear was negative if no $\mathrm{M}$. suis was observed.

Performances of qPCR and blood smear microscopy were compared to determine their clinical relevance. Specificity, sensitivity, positive predictive value (PPV) and negative predictive value (NPV) were estimated for Giemsa-stained blood smears using qPCR as the Gold Standard. The number of $M$. suis $16 \mathrm{~S}$ gene copies per millilitre for each blood smear result (positive, doubtful or negative) were shown in box-plots using median, quartiles, minimum and maximum. Comparison of means was made using the Kruskal-Wallis test. Statistical significance was set at $p<0.05$.

\section{Results}

Samples were collected from 199 sows, but comparison between qPCR and blood smears microscopic observation results could only be carried out on 191 samples because of unreadable blood smears. For the detection of M. suis

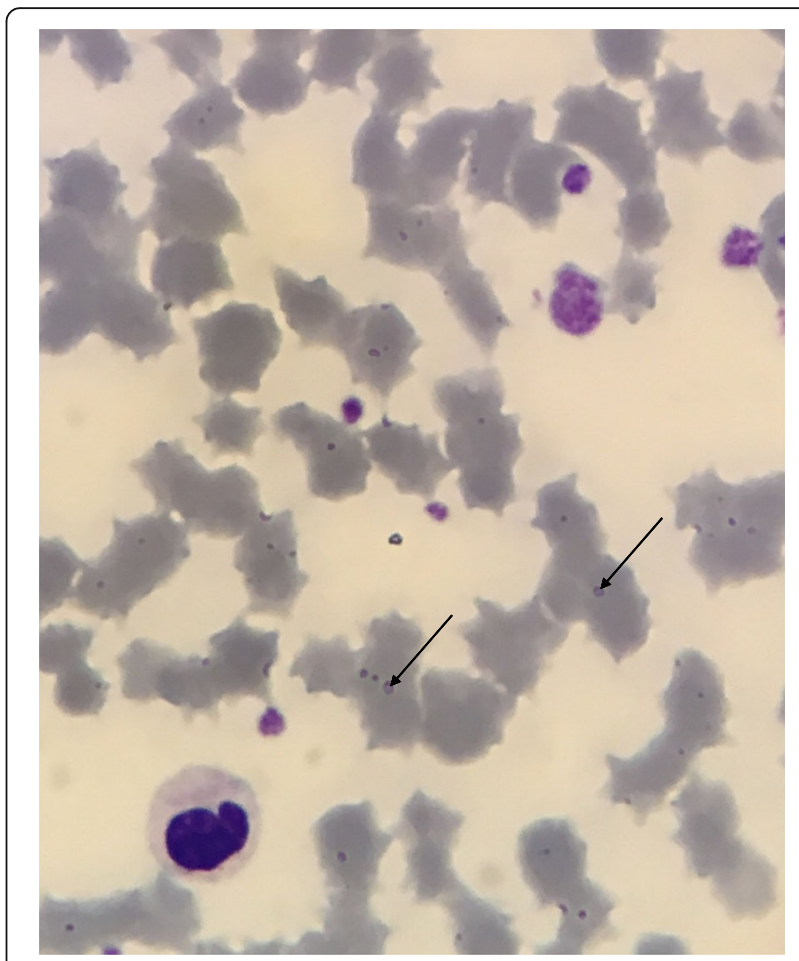

Fig. 1 Light microscopic image of a Giemsa-Grünwald-stained infected blood smear. M. suis is identified with arrows $(\times 1,000)$

with blood smears, 42 samples were positive, 41 were doubtful and 108 were negative. For qPCR, 102 samples were positive and 89 were negative. Doubtful microscopy observations, on which no $M$. suis could be visualised were considered as negative for the estimation of sensitivity, specificity, PPV and NPV (Table 1). Considering qPCR as the reference standard diagnostic tool for the detection of $M$. suis, we first determined a specificity of $90 \%$, a sensitivity of $32 \%$, a PPV of $79 \%$ and an NPV of $54 \%$ for the microscopic observation of Giemsa-stained blood smears. Excluding unquantifiable positive qPCR results, we found no statistical relationship $(p>0.05)$ between mean $\mathrm{qPCR}$ loads and blood smear results (Fig. 2). At farm level, two farms out of ten were incorrectly classified as negative based on blood smears (Table 2).

\section{Discussion}

The study aimed to determine the clinical relevance of Giemsa-stained blood smear for the diagnosis of

Table 1 Classification of qPCR and blood smear results

\begin{tabular}{lllll}
\hline & & \multicolumn{2}{l}{ GPCR } & Total \\
\cline { 3 - 4 } & & Positive & Negative & \\
\hline \multirow{3}{*}{ Blood smear } & Positive & 33 & 9 & 42 \\
& Negative & 69 & 80 & 149 \\
& Total & 102 & 89 & 191 \\
\hline
\end{tabular}




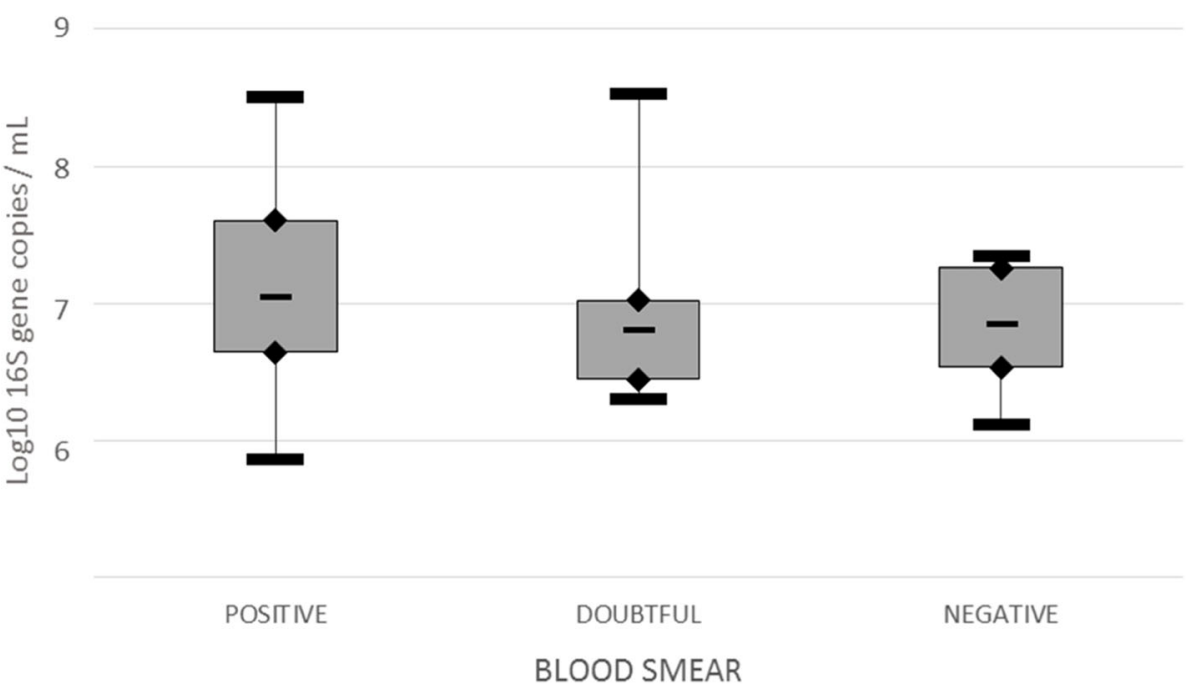

Fig. 2 qPCR loads of M. suis positive, doubtful or negative sows based on blood smear microscopy. This graph is based on logarithmic scaling excluding $\mathrm{qPCR}$ unquantifiable results

M. suis compared with qPCR results. Indeed, qPCR is considered as the most effective method for the identification of M. suis [3]. In our study, we observed a low sensitivity of blood smear microscopy. Microscopic observation of the organism on the surface of erythrocytes in Giemsa-stained blood smears was demonstrated of poor relevance in acute infection ([3]; Hoelzle et al., 2007) because the parasites are not always apparent unless parasitaemia is present [6]. Chronic haemoplasma infections in pigs with low or undetectable numbers of parasites in peripheral blood smears are well recognized [5]. Limited number of $M$. suis on and between erythrocytes in the acute and chronic phases could explain the low sensitivity of blood smear microscopy compared with qPCR [1]. $M$. suis can invade erythrocytes [1], which explains why the bacteria is detected by qPCR, sometimes with high bacterial loads, without microscopic detection. In other words, qPCR is probably the best diagnostic tool available today for the diagnosis of $M$. suis in veterinary practice. However, nine samples were only positive in blood smears. Two explanations could be exposed. These unexpected results could be linked to qPCR inhibitors in samples or could be false positive results in blood smears microscopic observations. Indeed, false positive microscopic results are possible by confounding $M$. suis and immature DNA harbouring erythrocytic structures [7].

\section{Conclusion}

This study demonstrated the low sensitivity and the poor clinical relevance of blood smear microscopy for the detection of $M$. suis in chronically affected sows. Although more costly, qPCR is probably the best diagnostic tool available today for $M$. suis diagnosis.

Table 2 Intra-herd rate of positive sows depending on diagnostic tool used (Giemsa-stained blood smear or qPCR)

\begin{tabular}{lll}
\hline Herd & Rate of positive sows based on Giemsa-stained blood smears results & Rate of positive sows based on qPCR results \\
\hline A & $22.2 \%$ & $50.0 \%$ \\
B & $57.9 \%$ & $94.7 \%$ \\
C & $26.3 \%$ & $63.2 \%$ \\
D & $15.0 \%$ & $55.0 \%$ \\
E & $10.5 \%$ & $47.5 \%$ \\
F & $20.0 \%$ & $40.0 \%$ \\
G & $21.1 \%$ & $52.6 \%$ \\
H & $0 \%$ & $30.0 \%$ \\
I & $0 \%$ & $5.9 \%$ \\
J & $40.0 \%$ & $90.0 \%$ \\
\hline
\end{tabular}




\section{Acknowledgements}

Not applicable.

\section{Authors' contributions}

Study conception and design: GB, VN, AL. Data acquisition: MB, GB, VN, PYM, VB. Data analysis and interpretation: AL, GB, VN. Drafting the manuscript: GB,

VN. All authors read, critically revised and approved the final manuscript.

\section{Funding}

The sponsor of the study was Porc.Spective Swine Vet Practice and Finalab Veterinary Laboratories Group.

\section{Availability of data and materials}

All datasets used in this study are available from the corresponding author on reasonable request.

\section{Ethics approval and consent to participate}

This study was performed in accordance with the French national current legislation on ethical and welfare recommendations. Blood samples analysed in this study come from a veterinary practice for general diseases diagnosis. No specific authorization or declaration was needed in this case.

\section{Consent for publication}

All authors gave their consent for publication.

\section{Competing interests}

The authors declare no conflict of interest.

\section{Author details}

'Porc.Spective Swine Vet Practice, ZA de Gohélève, rue Joseph et Etienne Montgolfier, 56920 Noyal Pontivy, France. ${ }^{2}$ Orbio Finalab Veterinary Laboratory Group, 12 rue du 35ème regiment d'aviation, 69500 Bron, France. ${ }^{3}$ Labofarm Finalab Veterinary Laboratory Group, 4 rue Théodore Botrel, 22600 Loudéac, France.

Received: 25 October 2019 Accepted: 30 December 2019

Published online: 20 February 2020

\section{References}

1. Groebel K, Hoelzle K, Wittenbrink MM, Ziegler U, Hoelzle LE. Mycoplasma suis invades porcine erythrocytes. Infect Immun. 2009;77:576-84. https://doi. org/10.1128/IAl.00773-08

2. Guimaraes AMS, Vieira RFC, Poletto R, Vemulapalli R, Santos AP, de Moraes W, Cubas ZS, Santos LC, Marchant-Forde JN, Timenetsky J, Biondo AW Messick JB. A quantitative TaqMan PCR assay for the detection of mycoplasma suis. J Appl Microbiol. 2011;111:417-25. https://doi.org/10. 1111/j.1365-2672.2011.05053.x.

3. Hoelzle LE. Haemotrophic mycoplasmas: recent advances in mycoplasma suis. Vet Microbiol. 2008;130:215-26. https://doi.org/10.1016/j.vetmic.2007.12.023.

4. Hoelzle LE, Zeder M, Felder KM, Hoelzle K. Pathobiology of mycoplasma suis. Vet J. 2014;202:20-5. https://doi.org/10.1016/j.tvjl.2014.07.023.

5. Messick JB. Hemotrophic mycoplasmas (hemoplasmas): a review and new insights into pathogenic potential. Vet Clin Pathol. 2004;33:2-13.

6. Messick JB, Cooper SK, Huntley M. Development and evaluation of a polymerase chain reaction assay using the 16S rRNA gene for detection of Eperythrozoon Suis infection. J Vet Diagn Investig. 1999;11:229-36. https:// doi.org/10.1177/104063879901100304

7. Ritzmann M, Grimm J, Heinritzi K, Hoelzle K, Hoelzle LE. Prevalence of mycoplasma suis in slaughter pigs, with correlation of PCR results to hematological findings. Vet Microbiol. 2009;133:84-91. https://doi.org/10. 1016/j.vetmic.2008.06.015.

\section{Publisher's Note}

Springer Nature remains neutral with regard to jurisdictional claims in published maps and institutional affiliations.

\section{Ready to submit your research? Choose BMC and benefit from:}

- fast, convenient online submission

- thorough peer review by experienced researchers in your field

- rapid publication on acceptance

- support for research data, including large and complex data types

- gold Open Access which fosters wider collaboration and increased citations

- maximum visibility for your research: over $100 \mathrm{M}$ website views per year

At BMC, research is always in progress.

Learn more biomedcentral.com/submissions 